\title{
Pesquisa
}

\section{REPRESENTAÇÕES SOCIAIS DOS \\ PROFESSORES SOBRE AFETIVIDADE}

Manoela Bernardo de Sousa (1)

\begin{abstract}
Resumo
Este estudo discute a compreensão do conteúdo e da estrutura das representações sociais de professores do ensino fundamental sobre afetividade. O instrumento utilizado foi uma associação livre de palavras, através de uma entrevista semi-estruturada. Concluímos que a afetividade, se traduziu como um sentimento positivo, eliciador de amor, atenção, carinho, amizade e afeição entre as pessoas. Também emergiu uma segunda categoria onde a afetividade se mostrou como um recurso capaz de fortalecer vínculos pessoais, familiares e as relações educacionais.
\end{abstract}

Palavras-chave: afetividade; relação educativa; representações sociais.

\section{Introdução}

O presente trabalho, é mais um estudo no âmbito das Representações Sociais. Os mesmos são importantes para a construção do ser humano nas diversas esferas da sociedade inclusive nas esferas educativa, social e principalmente humana.

É de grande valia e importância social e educacional levar a diante mais estudos sobre esta temática, para que se forme uma maior base teórica, de forma a propiciar um maior entendimento de aspectos possam ajudar na promoção de uma vida acadêmica mais saudável e com maiores possibilidades de resultados. Portanto, o objetivo aqui foi de ser um instrumento a mais na compreensão desse construto (Afetividade), não havendo pretensão conclusiva.

Diante destes aspectos, parece relevante e justificável compreender como se dá as Representações Sociais de Afetividade no processo educacional. Os professores têm uma parcela de responsabilidade quanto a transmissão desse tipo de valor humano. Neste sentido, conhecer as Representações Sociais e em que medida esses influenciam as motivações acadêmicas e as relações pessoais na escola passa a ser essencial. Garantir uma educação humanizada e de qualidade, requer reconhecer o que afeta a essas crianças e estimar o quanto elas podem estar comprometidas consigo mesmas, com sua educação e com os valores humanos como a afetividade. Os objetivos principais deste estudo, portanto, são: examinar as representações sociais de afetividade entre professores do 
ensino fundamental, caracterizar a amostra de professores sócio-culturalmente e, conhecer as representações de si mesmos destes professores. Neste caso, tendo-se em conta professores do ensino fundamental do Colégio Gênius, no município do Juazeiro do Norte, estado do Ceará.

Num primeiro momento o presente artigo enfocará os principais referenciais teóricos relativos ao tema Afetividade. Em seguida o tema das Representações Sociais é tratado mais amplamente, discutindo-se suas definições e recuperando os modelos teóricos principais. Seguem-se os objetivos gerais e específicos do estudo e explicação detalhada do método e procedimentos. Ao final, procedemos a análise dos resultados e finalmente apresentamos algumas considerações finais.

Este artigo pretende oferecer uma contribuição através da disponibilização de informações, principalmente, sobre Representações sociais de Afetividade entre educadores do ensino fundamental. Iniciaremos pois, com o construto, objeto do presente estudo. A afetividade.

\section{Afetividade}

Em geral o conhecimento tem sido considerado como algo separado da emoção. A dicotomia entre "razão" e "emoção" perdurou por longas eras e foi muito defendida por filósofos de relevância imensa, tal como René Descartes. Essa cisão influenciou fortemente toda a nossa maneira de organização social e inclusive nossa forma de refletir e pensar sobre os mais diferentes aspectos da convivência humana, inclusive a educação. No entanto, apesar de trazer benefícios, essa concepção trouxe também muitos problemas para educadores e alunos, sendo o maior deles o descaso para com a relação afetiva entre professor e aluno. É comum entre os educadores, desde o Ensino Fundamental até o Ensino Superior, a idéia de que o seu dever é o de entrar na sala de aula e repassar o conteúdo da aula, sendo que o aproveitamento (ou não-aproveitamento) depende única e exclusivamente do aluno.

$\mathrm{O}$ conhecimento se transformou em produto e o ensino em comércio. Professores, coordenadores e inclusive pais, se esqueceram que, muito mais do que uma empresa, a empreitada educacional é uma missão humanizadora. Seus objetivos não devem ser o lucro (ainda que este possa ocorrer), mas sim a propagação da cultura universal, a inclusão social e, mais importante do que tudo, a formação plena do homem. E para que haja essa formação plena, é preciso muito mais do que a

simples transmissão de um conteúdo científico. É preciso que a escola se converta em um ambiente humano, em um ambiente afetivo.

Propostas novas na pedagogia vem sendo desenvolvidas a fim de trabalhar o aspecto da afetividade no relacionamento professor-aluno. É o caso do trabalho do pedagogo Albert Bandura (1986). Bandura defende a tese de que uma importante ferramenta de ensino é a auto-regulação. Essa insiste na capacidade do aluno avaliar a si mesmo no decorrer de seu aprendizado e redirecionar-se para obter êxito. Um fator que influencia no desenvolvimento da auto-regulação, segundo o pedagogo, é a qualidade da relação professor-aluno. Bandura aponta que a afetividade entre educador e educando 
pode ajudar a ativar os processos de auto-avaliação na medida em que ela permite um relacionamento mais significativo entre o aluno e o conteúdo a ser aprendido. Assim, a afeição entre professor e aluno atua como ponte para atingir os objetivos da educação, sendo de crucial importância.

É preciso que a educação brasileira volte-se mais para as questões que envolvem esse relacionamento complicado do educador e seus educandos. Relacionamento esse que precisa ser saudável e bem desenvolvido, permitindo que a sala de aula seja um ambiente mais humano, caloroso, agradável e que de fato propicie a apropriação e criação do conhecimento e da cultura humana. Professores, coordenadores, pais e alunos precisam compreender melhor o papel da afetividade na escola para que esta de fato atinja seus objetivos principais: a formação de seres humanos.

O objetivo do presente estudo foi examinar as representações sociais de afetividade entre professores do ensino fundamental. Diversos autores (Pereira, 1991; Araújo, 1995; Cianfa, 1996; Rodríguez, Plax e Kearney, 1996; Testerman, 1996; Camargo, 1997; Moll, 1999; Côté, 2002; Espinosa, 2002 e Dias, 2003) consideram que a afetividade contribui para a aquisição de atitudes positivas em relação a professores, às disciplinas por eles ministradas e, conseqüentemente, para a aprendizagem cognitiva dos alunos na sala de aula. Moll (1999) destaca a importância da relação afetiva como propiciador de uma maior relação com o saber. Para Codo e Gazzotti (1999), é por meio da afetividade que se estabelecem as relações afetivas necessárias a realização do processo de ensinoaprendizagem. Outros estudos mostram que as dificuldades na aprendizagem são produtos de nãoajustamentos entre professores e alunos e que, portanto, se constroem na sala de aula, nas interações pedagógicas. Dessa forma, nos indagamos, qual as representações dos professores do ensino fundamental sobre afetividade?

Damásio (2000) e Assmann (1998) postulam que a aprendizagem depende da emoção e da valorização do corpo, motivo pelo qual os modelos que levam em conta apenas o aspecto intelectual são questionados. O discurso oficial sugere aos formadores dos professores a inclusão, nos programas de formação, de uma série de competências que ultrapassam a transmissão de um saber codificado numa disciplina (Brasil, 1999). Dentre outras, assegura o desenvolvimento da competência afetiva na relação educativa. No entanto, na prática dos professores e nos currículos dos cursos de formação, em diversas universidades brasileiras, as relações afetivas ainda não encontraram um lugar de equilíbrio no que concerne à dimensão cognitiva.

A afetividade, neste trabalho, inscreve-se na relação educativa que se estabelece entre professor e alunos na sala de aula. Do nosso ponto de vista, a dimensão afetiva pode se desenvolver por meio da formação e é impulsionada pela expressão dos sentimentos e das emoções.

A afetividade, o amor e a dedicação dispensada pelo professor aos seus alunos e suas representações sociais de Afetividade, foram o foco de interesse deste estudo. Partindo de fontes diversas, que incluíram depoimentos e entrevistas, buscamos aprofundar-nos na compreensão das atitudes, crenças e comportamentos dos educadores do estado do Ceará. 
Segundo Moscovici (1984, p.251), é a "Representação social compreendida como a elaboração de um objeto social pela comunidade, com o propósito de conduzir-se e comunicar-se", portanto um instrumento de agregação e de socialização do saber de um grupo social.

Quando relaciona o estudo das representações com a linguagem, Madeira (1998, p.9) nos afirma que,

O estudo das representações sociais de um dado objeto, portanto, possibilita aproximar-se do movimento pelo qual o homem, continuamente, se apropria do mundo e, nele, se define, age e se comunica; Neste processo, o homem é autor e agente, enquanto torna o mundo palavra articulada, nos objetos de que se vai apropriando.

A teoria das representações sociais têm um papel fundamental na dinâmica das relações sociais e nas práticas, que responderia a quatro funções essenciais. Segundo Abric (1998), as representações enquanto função de orientação, guiam os comportamento e as práticas, definindo regras - sobre o que é lícito ou aceitável, conforme a expectativa do grupo - que unem socialmente os seus membros.

\section{Representações Sociais}

As representações sociais compreendem formas de conhecimento do senso comum, quer dizer, organizadas e partilhadas socialmente, que servem para tornar compreensível e comum a realidade na qual os indivíduos de um grupo estão inseridos como sujeitos. Constituem-se de um conjunto organizado de conceitos, de proposições e de explicações criadas na vida cotidiana, durante as comunicações interpessoais dos grupos, para guiar os comportamentos e as práticas sociais de modo a traduzir a posição e a escala de valores de um indivíduo ou de uma coletividade.

Segundo Lage (2002), depois de 1970, coexistem duas abordagens para se estudar as representações sociais. A primeira, denominada societal, correspondente à orientação original de Serge Moscovici e de Denise Jodelet, estuda as representações em função do lugar em que o grupo ocupa na sociedade. A segunda, denominada estrutural, interessa-se pela maneira como um determinado objeto é construído do ponto de vista cognitivo. Nessa abordagem, as representações são estudadas a partir das respostas de um grupo homogêneo. Assim, não há interesse em relação ao aspecto social, mas, sem, à estrutura da própria representação. Uma representação é formada de elementos constitutivos (informações, crenças, opiniões e atitudes) (Abric, 1997), organizados e estruturados de acordo com a hipótese: "toda representação é organizada em torno de um núcleo central" (Abric, 1989; 1997). A essa proposição, mais tarde, Flament acrescenta a idéia de elementos periféricos (Moliner, 1995), uma 
vez que esses elementos, tomados como circunstanciais e acessórios em referência aos elementos do núcleo, eram provavelmente excluídos das preocupações dos pesquisadores.

Não obstante, de acordo com Lage (2002), o sistema periférico é mais rico e complexo do que o sistema central. Essa autora defende que as relações entre as representações e a prática podem ser examinadas a partir do estudo dos elementos periféricos e que descobrir o sistema central nos permitiria descobrir coisas óbvias, já conhecidas. No entanto, tal idéia não é partilhada por grande parte dos estudiosos da teoria das representações sociais. O núcleo central está ligado e determinado por condições históricas, sociológicas e ideológicas, marcado pela memória coletiva e pelo sistema de normas. Evolui de forma lenta. É ele quem atribui ou transforma a significação (um sentido, um valor) ao objeto representado; assegura a permanência e a perenidade da representação; permite compreender a realidade; dá homogeneidade ao grupo e define os princípios fundamentais em torno dos quais se constituem as representações; é simples, concreto, consensual, historicamente marcado, imagético e coerente; apresenta um valor simbólico, poder associativo, saliência e forte conexidade na estrutura. Não pode ser refutável (Moliner, 1995).

A teoria das representações sociais nos permite compreender o sentido que os professores, em sua prática, atribuem à afetividade e a natureza dos obstáculos que eles encontram para efetivar um processo educativo que leve em conta a dimensão afetiva. Por meio das representações, tomamos conhecimento das maneiras pelas quais os professores estabelecem relações com seus alunos e da influência dessas relações no processo educativo. Uma vez que as práticas se realizam em consonância com as representações dos professores, torna-se possível identificar, por meio do discurso desses profissionais, as concepções e as ações que interferem, positiva ou negativamente, nos resultados da aprendizagem dos alunos.

Objetivamos aqui, examinar as representações sociais de afetividade entre professores do ensino fundamental, do Colégio Gênius, no município do Juazeiro do Norte, estado do Ceará. Trata-se de uma Instituição de ensino situada no bairro Salesianos, Juazeiro do Norte, estado do Ceará, fundada em 1998 e que atende da Educação Infantil ao Ensino Fundamental II. Conta com dezesseis professores, dois auxiliares de administração, dois coordenadoras, dois recepcionistas e, três auxiliares de limpeza em dois turnos diurnos (manhã e tarde).

Desde a sua fundação esta instituição revela um trabalho baseado no acolhimento e na perspectiva de formação da cidadania, correspondendo com as expectativas dos familiares que, matriculam suas crianças sabendo que serão respeitadas nas suas individualidades e atendidas as suas necessidades de carinho, segurança e educação.

A escolha da escola deveu-se a uma aproximação da pesquisadora com a instituição.

Os dados foram obtidos a partir de entrevistas semi-estruturadas, contendo questões de associação livre de palavras. As informações foram coletadas diretamente dos entrevistados, através de formulário, construído para o propósito da pesquisa.

Fizeram parte desta pesquisa 15 professoras, com idades variando entre 21 e 37 anos. 
Os participantes responderam a um instrumento, contendo as seguintes partes:

a) Um Questionário contendo Associação Livre de Palavras. O Teste de Associação Livre de Palavras (Jung,1905) é um tipo de investigação aberta que se estrutura na evocação de respostas dadas a partir de quatro estímulos indutores, o que permite colocar em evidência universos semânticos de palavras que agrupam determinadas populações. Esse instrumento já foi experimentado e validado em pesquisas realizadas sobre representações sociais (De Rosa, 1988; Le Boudec,1984). Segundo Abric (1994b), este instrumento permite a "atualização de elementos implícitos ou latentes que seriam perdidos ou mascarados nas produções discursivas" (p.66).

A análise de conteúdo é, segundo Vala (1986), uma das técnicas mais comuns em pesquisas empíricas realizadas em diferentes ciências humanas e sociais. No que tange à análise temática, enfatiza-se a análise de ocorrências, objetivando revelar a atenção dada pelos sujeitos entrevistados ao discurso, conferindo-lhe diferentes conteúdos inventariados. Observa-se que esse tipo de análise permite inferências sobre a organização do sistema de pensamento dos sujeitos.

Bardin (1977), afirma ser a análise de conteúdo:

um conjunto de técnicas de análise das comunicações visando obter, por procedimentos sistemáticos e objetivos de descrição do conteúdo das mensagens, indicadores (quantitativos ou não) que permitem a inferência de conhecimentos relativos às condições de produção/recepção (variáveis inferidas) destas mensagens... (p 42).

Vala (1986) comenta os aspectos conceituais da análise de conteúdo abordada por diferentes autores, afirmando que:

... o caráter objetivo e sistemático da análise de conteúdo referido por Berelson e Cartwright e as condições de validade e replicabilidade expressa por Krippendorff enquanto técnica de pesquisa, a análise de conteúdo exige a maior explicitação de todos os procedimentos utilizados ...(p.103).

Assim sendo, esta técnica, enquanto analisa as condições de produção do discurso, efetua inferências sobre as mensagens inventariadas e sistematizadas, articulando o discurso com o contexto de produção.

b) Informações Sócio-Demográficas: Foi proposto um conjunto de perguntas visando caracterizar a amostra, a exemplo de idade, sexo, religião e escolaridade.

As conclusões finais foram obtidas através de uma análise de conteúdo, visando-se chegar a uma compreensão das representações sociais de afetividade que, de alguma forma orientam as ações e 
comportamentos em uma sala de aula. A escolha da teoria se justifica, tendo em vista que, segundo Coutinho (2001, p.65),

A utilização da teoria das representações sociais, no diagnóstico psicossocial é bastante útil, à medida que se lida com um marco conceitual que envolve, tanto o nível intrapessoal de análise, como o interpessoal e o grupo; desta forma, é possível partir das representações sociais, para um exame das cognições no nível grupal, que permitem ao pesquisador, a apreensão dos aspectos compartilhados de uma representação.

\section{Resultados}

\section{Representações Sociais de Afetividade}

Baseando-se nesse contexto teórico-metodológico, utilizou-se a análise de conteúdo, tomando-se por base os objetivos propostos nesse estudo, subsidiados na teoria das Representações Sociais.

O corpus foi constituído por quinze entrevistas, onde constavam destas um formulário uma Associação Livre de Palavras, distribuídas entre sujeitos. Após a leitura flutuante do corpus, foram definidas as categorias emergentes (empíricas) e codificadas. Para a escolha das unidades de análise, esta técnica baseou-se na abordagem de Vala (1986). Em sua abordagem, geralmente, só existem dois tipos de unidades: formais e semânticas. As unidades formais incluem palavras, frases, um personagem ou a intervenção do locutor; as unidades semânticas compreendem o tema ou a unidade de informação.

Neste estudo, optou-se pelas unidades de contexto, que, segundo definições do referido autor, são compreendidas pelos segmentos mais largos de conteúdo.

Após a decomposição do corpus e a codificação dos temas agrupou-se o material em subcategorias e categorias.

O corpus foi agrupado em duas categorias, de acordo com o quadro 1 a seguir.

Quadro 1: Distribuição das Categorias e Subcategorias da Afetividade

\begin{tabular}{|c|c|}
\hline Categorias & Subcategorias \\
\hline$\frac{\text { CATEGORIA } 1 \text { - (PA) }}{\text { Percepção da Afetividade }}$ & - Sentimento Positivo \\
\hline $\begin{array}{l}\text { CATEGORIA } 2-(\mathrm{IA}) \\
\text { Importância da Afetividade }\end{array}$ & - Facilitadora de Relacionamentos \\
\hline
\end{tabular}


A CATEGORIA 1 - (PA), refere-se Percepção de Afetividade, onde sobressaiu-se apenas uma subcategoria: Sentimento positivo. Neste caso a afetividade foi concebida como uma expressão humana, que se traduz em forma de: carinho (25); amor (15), atenção (5); dedicação (6), amizade (15), união (9), companheirismo(8), ternura (7), querer bem (7), afeição (10); emoção (5); apego (2) . Também eliciou a Percepção da Afetividade como: lindo sentimento (1);sentimentos e paixões (2); pessoa que se identifica com outra (1); necessidade (1); e, estado de ânimo humano (1).

A CATEGORIA 2 - (IA) refere-se a Concepção da Importância da Afetividade, onde sobressaiuse uma subcategorias: Facilitadora de relacionamentos. Neste caso, a afetividade foi percebida como propiciadora de uma melhor relação pessoal, familiar e educativa entre as pessoas, observe-se nas palavras evocadas: maternidade (1); paternidade (1); afiliação(1); relação conjugal (1); família (2); amigo(1), uma vez que elicia estados de conforto (1), e fortalece valores como: harmonia(4), respeito (2), auto-estima(1), moral(1), fidelidade (1), sinceridade(1), compromisso(1), dedicação (1).

\section{Representações Sociais de "Eu mesmo"}

De uma maneira geral, pudemos observar que uma parte dos sujeitos se reconheceu de maneira positiva, percebendo em si características relacionadas a Possibilidades e Emoções. Outro grupo se reconheceu de uma forma mais negativa, evocando uma percepção de Egoísmo e individualismo, como pode ser observado pelas falas dos participantes, a seguir:

CATEGORIA 1 - POSITIVA, com duas sub-categorias:

a) Possibilidades. Neste caso, os professores se reconheceram como pessoas capazes de lidar com suas atribuições sociais. Essa subcategoria ficou demonstrada através das seguintes falas: "responsabilidade (2); sucesso; vitória; acredito em mim; eu sou capaz; vencer problemas; dedicada; determinada (2); participação; companheirismo; descoberta; construção; conhecimento; amadurecimento; família; amistosa, solidária.

b) Emoções. Neste caso, suas Representações de si mesmos denotaram uma visão de si, como pessoas que guardam valores humanos e emocionais, tais como: prudência, felicidade, carinhosa, idealista, moralista.

CATEGORIA 2 - NEGATIVA, com uma sub-categoria:

a) Egoísmo. Neste caso, os sujeitos se reconheceram como pessoas egoístas e individualistas. 
A descrição das representações dos professores sobre afetividade nos leva a um nível de conhecimento que corresponde, particularmente, à descoberta e à exploração dos elementos constitutivos (conteúdo) dessas representações e da organização dos seus elementos. Escolhemos para participantes do estudo os professores do Colégio Gênius - Juazeiro do Norte, que estão atuando no ensino fundamental, com a possibilidade, portanto, do exercício da competência afetiva na relação educativa.

A coleta de dados fez-se em única etapa, com o intuito de recolher os elementos constitutivos do conteúdo da representação de afetividade, convocamos 15 professores para a realização de associações livres. Os participantes foram induzidos a escrever os substantivos, adjetivos, verbos e expressões sinônimas do termo indutor "afetividade", o que resultou em 145 evocações.

Em seguida foi solicitado aos mesmos professores que redigissem palavras que pudessem representar " eu mesmo", isso é, que pudessem representar a si mesmos. Buscando um testemunho completo por meio do discurso livre e espontâneo dos participantes, as entrevistas foram realizadas a partir de um guia composto por três um só questionário com as questões e "provocadoras" que versavam sobre as representações de afetividade e de si mesmos.

Para a análise dos dados, recorremos a metodologias mistas, as quais contêm elementos pertencentes às abordagens qualitativa e quantitativa. Assim, a fim de analisar as produções obtidas mediante as associações livres, extraímos, do total das 145 palavras evocadas, das quais 25 eliciações (17\% do total) foram relativas a palavra "carinho".

Quanto às produções das entrevistas, a análise se deu mediante as fases da análise do conteúdo sugeridas por Bardin (2001), resultando em duas categorias, das quais consideramos mais relevante a presença do que a freqüência dos elementos.

Inicialmente, discutimos os dados provenientes da associação livre. Dentre as 145 evocações, constatamos, no discurso dos participantes, a saliência de alguns termos. A palavra carinho foi citada com a maior frequiência (17\%), seguida pelas palavras amor(10\%),amizade(10\%) e afeição(5,5\%), dentre outras.

Com os resultados precedentes, organizamos um sistema de categorias a partir dos elementos que possuem poder associativo em relação aos demais. Obviamente, esses elementos possibilitaram o surgimento de duas categorias de agrupamento: Sentimento Positivo e Facilitadora de relacionamentos, já referidas anteriormente.

No caso da percepção de si mesmas, as educadoras se perceberam, em sua maioria de uma forma positiva, onde evocaram palavras relativas a Possibilidades e Emoções, com 90\% das palavras evocadas. Uma categoria negativa também foi eliciada de maneira mais tímida, relacionada com o Egoísmo e Individualismo, porém com baixa frequiência de aparições (10\%) em relação ao total. 


\section{Considerações Finais}

Este estudo nos possibilitou apreender o conteúdo das representações compartilhadas de afetividade dos professores que atuam no ensino fundamental do Colégio Gênius, e obter informações sobre a prática educativa desses profissionais.

Os professores atestam, de forma consensual, que a afetividade é importante para que se estabeleça uma melhor relação educativa entre professores e alunos, favorável, conseqüentemente, à aprendizagem dos conteúdos escolares.

Destacamos, nos seus discursos, em conversa informal, que o quadro de promiscuidade imposto pela mídia e, de carência afetiva, no qual vive uma parte dos alunos da escola brasileira, hoje, por conta de uma série de questões sociais e de trabalho, impõe-se como um desafio para o professor, o qual necessita compreender e oferecer a atenção a esses alunos, a fim de lhes ajudar a progredir no processo de aprendizagem.

As representações dos participantes conduzem a um protótipo ou modelo desejável de professor afetivo (haja vista as categorias eliciadas: Sentimento Positivo e Facilitadora de relacionamentos): um professor centrado na pessoa do aluno, que compreende suas necessidades e as inclui no planejamento do ensino e que busca desenvolver, na sala de aula, atividades criativas, dinâmicas e que demandam participação, nas quais os alunos, em grupo, aprendem a convivência Apesar dessa crucial necessidade, os professores confirmam que os cursos de formação de professores na universidade não atribuem à competência afetiva na relação educativa o devido destaque. A representação positiva em relação à afetividade permite-lhes sugerir aos formadores a ênfase na construção dessa competência, a fim de que eles possam refletir e rever suas práticas educativas com a pretensão de não contribuírem para a produção do fracasso escolar.

Os professores como atores sociais constroem suas representações a partir do conjunto de idéias, opiniões, informações e crenças presentes no seu contexto sociocultural, de modo que tais representações constituem referência para a prática desenvolvida em sala de aula. Então, o ato de tocar ou de olhar o aluno na sala de aula, que pode interferir na eficácia do processo educativo, parece condicionado pelas avaliações morais do grupo social.

Finalmente, quanto à organização do conteúdo das representações de afetividade, constatamos que o núcleo central dessas representações pode ser constituído dos elementos: amor, carinho, compreensão, respeito, amizade, afeto, solidariedade, atenção e companheirismo e que esses elementos aglutinadores desempenham um papel importante na relação educativa.

Segundo Oliveira e Callou (2006), a consciência da percepção de si, permite ao indivíduo a internalização mais abrangente através da experiência direta. Objetiva oferecer oportunidades aos indivíduos de internalizar e abraçar idéias experimentados durante o processo vivencial, que no caso foi a própria experiência de escrever sobre si mesmos. 
Assim, no caso da percepção de si, o estudo parece ter proporcionado um maior contato com sentimentos em relação à auto-imagem dos sujeitos. O estudo possibilitou uma maior conscientização de suas atitudes e percepção de si mesmos, promotores de um maior autoconhecimento.

\section{Referências}

ABRIC, J.-C. Les représentations sociales : aspects théoriques. In J.-C. Abric (Dir.). Pratiques sociales et représentations (2.ed., pp.11-37).Paris: Presses Universitaires de France, 1977.

ABRIC, Jean-Claude, A abordagem estrutural das representações sociais. In: Moreira, A.S.P. e Oliveira, C.C. de. (Orgs.) Estudos interdisciplinares de representação social. Goiânia: AB, 1998;

ARAÚJO, C. M. M. Relações interpessoais professor-aluno: uma nova abordagem na compreensão das dificuldades de aprendizagem. Dissertação de mestrado não-publicada, Instituto de Psicologia, Universidade Nacional de Brasília, 1995.

ASSMANN, H. Reencantar a educação: rumo à sociedade aprendente. Petrópolis: Vozes, 1998.

BANDURA, A. Social foundations of thought and action: a social cognitive theory. Englewood Cliffs, N. J.: Prentice-Hall, 1986.

BARDIN, L. 1977 e 2001. Análise de conteúdo. Lisboa, 70 ed.

BELLO, José Luiz de P..Metodologia científica, disponível em $<$ http://www.pedagogia emfoco.pro.br > acesso em 21/01/2003;

BRASIL. Secretaria de Educação Fundamental. Referenciais para formação de Professores. Brasília: MEC, 1999.

CAMARGO, D. As emoções no processo de aprendizagem.Tese de doutorado não-publicada, Pontifícia Universidade Católica de São Paulo, 1997.

CIANFA, C. R. L. A importância das relações interpessoais na educação de adultos. Dissertação de mestrado não-publicada, Faculdade de Educação, Universidade Estadual de Campinas, 1996.

CODO, W., \& GAZZOTTI, A. A. Trabalho e afetividade. InW. Codo (Dir.). Educação, carinho e trabalho (3.ed., pp.48-59). Petrópolis: Vozes, 1999.

CÔTÉ, R. L. Faire des émotions et de l'affectivité des alliés dans le processus d'enseignementapprentissage. In L. Lafortune \& P. Mongeau (Dir.). L'affectivité dans l'apprentissage (pp.85114). Québec: Presses de l'Université du Québec, 2002.

DAMÁSIO, A. R. O sentimento de si: a emoção e a neurobiologia da consciência (8.ed.). Lisboa: Publicações Europa-América, 2000.

DIAS, A. M. S. O desenvolvimento pessoal do educador através da Biodança.Dissertação de mestrado não-publicada, Departamento de Educação, Universidade Federal de Alagoas, Maceió, 2003. 
ESPINOSA, G. La relation ma"tre-élève dans sa dimension affective: un pivot pour une différenciation des pratiques pédagogiques enseignantes? In L. Lafortune \& P. Mongeau (Dir.). L'affectivité dans l'apprentissage (pp.159-181). Québec: Presses de l'Université du Québec, 2002.

GIL, A. C. Como elaborar projetos de pesquisa. 3.ed. São Paulo: Atlas, 1996.

LAGE, E. Modelos e pesquisas no campo das Representações Sociais. Curso ministrado no Departamento de Ciências da Vida. Salvador: UNEB, 2002.

MADEIRA, Margot C. (org). Representações sociais e educação: algumas reflexões. Natal: EDUFRN, 1998;

MOLL, J. La dimension affective dans la formation des adultes.InG. Chappaz (Dir.). La dimension affective dans l'apprentissage et la formation (pp.103-130). Paris: SFP-UNAPEC, 1999.

MOLINER, P. A two-dimensional model of social representations. European Journal of Social Psychology,25 (1), 27-40, 1995.

MOSCOVICI, S. 1961. La psychanalyse son image et son public. Paris:Presses Universitaires de France.

1984, Psycologie Sociale, Paris: Press Universitaire de France, PUF;

PEREIRA, T. L. Comunicação professor e aluno em sala de aula. Dissertação de mestrado nãopublicada, Escola de Comunicações e Artes, Universidade de São Paulo, 1991.

RODRÍGUEZ, J. I., PLAX, T. G., \& KEARNEY, P. Clarifying the relationship between teacher nonverbal immediacy and student cognitive learning: affective learning as the central causal mediator. Communication Education, 45(4), 293-305, 1996.

TESTERMAN, J. Holding at-risk students: the secret is one-on-one. Phi Delta Kappan, 77 (5), 364-65, 1996.

Sobre a autora:

(1) Manoela Bernardo de Sousa é Bacharel em Letras Universidade Regional do Cariri - URCA. E-mail: sousamanoela21@yahoo.com.br

Como citar este artigo (Formato ISO):

SOUSA, M.B. Representações Sociais dos Professores sobre Afetividade. Id on Line Revista de Psicologia, Julho. 2010, vol.1, no.11, p.39-50. ISSN 1981-1189. 